\title{
The Young's Modulus and Impact Energy Absorption of Wet and Dry Deer Cortical Bone
}

\author{
John D. Currey ${ }^{1}$, Tomas Landete-Castillejos ${ }^{*, 2,3,4}$, Jose A. Estevez ${ }^{2,3,4}$, Augusto Olguin ${ }^{2,4}$, \\ Andres J. Garcia ${ }^{2,3,4}$ and Laureano Gallego ${ }^{2,3,4}$
}

${ }^{I}$ Department of Biology, University of York, York YO10 5YW, UK

${ }^{2}$ Grupo de Recursos Cinegéticos. Instituto de Desarrollo Regional (IDR). Universidad de Castilla-La Mancha (UCLM). 02071 Albacete, Spain

${ }^{3}$ Departamento de Ciencia y Tecnología Agroforestal, ETSIA, Universidad de Castilla-La Mancha (UCLM), 02071 Albacete, Spain

${ }^{4}$ Animal Science Tech. Applied to Wildlife Management Res. Group, IREC Sec. Albacete, Campus UCLM, 02071 Albacete, Spain

\begin{abstract}
We have shown recently that antlers of red deer, at the time that they are used in fights in the rut, are essentially dry. We have also shown that dry antler material has a lower impact energy absorption than that of wet antler, a property which, in a fight, is probably very important in the first clashing of antlers. However, dry antler has a much higher Young's modulus (stiffness) than wet antler, and this property will be important in the pushing match that follows the initial impact. These values were compared with those of wet bone, and it was found that although dry antler had a somewhat lower Young's modulus than wet bone, it had a much higher impact energy absorption. In that paper we did not consider the properties of dry bone. We now rectify that.

The present paper compares the Young's modulus and impact energy absorption of wet and dry antler with that of wet and dry long bone of deer. It is found that the Young's modulus of dry antler is slightly less (12\%) than that of wet long bone, which is in turn slightly less (7\%) than that of dry long bone. On the other hand the impact energy absorption of dry antler is much (x6.6) greater than that of wet bone and even greater (x14.3) than that of dry bone. (The impact energy absorption of wet antler could not be measured consistently; it was certainly very high).

We suggest that the material properties of antler (which is necessarily dry when used in fights) are superior to those of dry long bone material because, although they have somewhat lower (18\%) Young's modulus, they have a much greater (x14) impact energy absorption. The properties of wet long bone and wet antler material are given for comparison, but neither could be used in reality.
\end{abstract}

\section{INTRODUCTION}

It is known that water is a constituent of bone that has an important effect in reducing bone's Young's modulus of elasticity and quasi-static post-yield work [1-4]. However, the effects that hydration may have on other mechanical properties is less well known. In the course of another study on the question of the extent to which the antlers of Red Deer Cervus elaphus are dry when used in fighting, and the mechanical properties of antler in the dry and hydrated state, we found that hydration had the effect of reducing Young's modulus of elasticity (henceforth termed $E$ ), but increased quasi-static post-yield work, a property that seems to be greatly influenced by the organic phase of bone $[5,6]$.

*Address correspondence to this author at the Animal Science Tech. Applied to Wildlife Management Res. Group, IREC Sec. Albacete, IDR, UCLM, 02071 Albacete, Spain; Tel: +34-967599200 ext. 2654; Fax: +34967599233; E-mail: Tomas.Landete@uclm.es
Because wet antler often does not break in impact when wet, impact energy absorption (henceforth termed $U$ ) might be even more influenced than work by hydration state, and thus, we considered it would be useful to get some comparative data on the $E$ and $U$ properties of other deer cortical bone (femur in this case) both dry and hydrated. These we regard as the two most important mechanical properties when antlers are used in fights. We are also concerned with how good 'ordinary' bone material might be if used as the mineralised material in antlers, given that it would have to be dry when used.

The main aims of this paper, therefore, were first to assess the effect that hydration has on $E$ and $U$ of cortical bone and second to determine whether dry long bone or dry antler is a better material for use in the rut. We also considered some other questions: whether $E$ and $U$ are correlated and if hydration state affects such a relationship; how individual differences in bone quality between hinds affect these variables (i.e., if values of $E$ are similar for left 
and right femora of the same individual and thus correlate; and also whether a similar symmetry is found for $E$ and $U$ between specimens obtained from the internal and external side of the femur) and finally to assess how $\mathrm{Ca}$ content, which we may consider as a proxy for mineral content, influences the effect of hydration on $E$ and $U$.

\section{MATERIALS AND METHODS}

Femora were collected from 12 Red Deer hinds kept on a natural diet on a $32 \mathrm{Ha}$ plot in a deer private game estate "LM" (Abenojar, Ciudad Real, Spain; UTM 10 x $10 \mathrm{~km}$ coordinates: 30SUJ80). The protocol for all specimens reported in this paper is given in Table 1. For operational reasons we had to use females (hinds) rather than males (stags), which would have been marginally more satisfactory. All hinds were three years old and therefore well mature. They had been kept on the plot as a well-fed control group in an experiment on nutrition. No hind was allowed to become pregnant during the experiment (a process that would affect mineral mobilization, as mammals undergo considerable bone Ca resorption to support lactation [7]). The experiment was conducted according to European and Spanish guidelines for use of animals in research, and also approved by the ethical committee of our university.

Table 1. Protocol of the Treatment of the Specimens Discussed in this Paper

\begin{tabular}{|c|}
\hline Femora room-dried for 4 weeks \\
\hline Mean of Ca of 4 samples determined \\
\hline $\begin{array}{c}\text { Room-dried for } 4 \text { weeks } \\
\text { diaphysis }\end{array}$ \\
\hline Dry dimensions measured \\
\hline Mailed to York, dimensions re-measured \\
\hline Hanks solution for 3 days \\
\hline $\begin{array}{c}\text { Wet dimensions and wet } E \text { determined } \\
\text { from deflection at } 10 \text { N load }\end{array}$ \\
\hline Exposed to room air for 5 days \\
\hline Dry dimension and dry $E$ determined \\
from deflection at $10 \mathrm{~N}$ load \\
\hline Kept dry
\end{tabular}

Ca content was assessed at two sections of each femur for the nutrition experiment mentioned above. Because the relationship between $E$ or $U$ and Ca content was statistically unplanned, we used the Ca values of both points sampled per femur and of both femora of each individual to compute a mean per hind. Thus, correlations involving $\mathrm{Ca}$ content and mechanical properties are obviously less accurate than if we had determined $\mathrm{Ca}$ content by drilling the cortical layer at either side of specimens used for impact testing. Ca content was assessed from samples obtained from the cortical layer of the femur, roughly at the mid-length and upper part of the femur by a minidrill (Dremel Serie 300). Because we used specimens for bending tests of the same size as those mentioned below to relate to $\mathrm{Ca}$ content in another experiment, powder from cortical bone was obtained from each side of those bars and as close to their longitudinal centre as possible (i.e., we drilled exactly in the middle of the femur, and around the upper $3 / 4$ of the femur length). Metal from the wearing of the drill would have a negligible effect on the measurements of mineral. The resulting powder was weighed immediately after sampling, homogenized, and sieved through a $0.5 \mathrm{~mm}$ mesh. Subsequently, the samples $(0.5 \mathrm{~g})$ were dissolved with an acid solution $(60 \% \mathrm{HCl}, 20 \%$ $\mathrm{HNO}_{2}$ and $20 \% \mathrm{H}_{2} \mathrm{O}$ ). These samples were subjected to a second wet digestion which was carried out in the microwave oven (Perkin-Elmer Multiwave 3000, Boston MA) at $345 \mathrm{kPa}$ for $30 \mathrm{~min}$. The samples were examined with an atomic absorption spectrophotometer (Perkin-Elmer Plasma 400, Boston MA).

The femora were dried 4 weeks outdoors, then the femur was cut with a minidrill (Dremel Serie 300), and two specimens prepared from the lateral and medial cortices of the lower part of the bone (Fig. 1). The specimens were all cortical bone, no cancellous bone was included. The specimens were polished in a Struers machine (Labopol 21) to dimensions of $4.5 \mathrm{~mm}$ (wide), $2.5 \mathrm{~mm}$ (depth). They had a minimum length of $45 \mathrm{~mm}$. They were then room-dried for four weeks before being sent, dry, to York. The dimensions of these dry specimens were measured both in Spain and then in York, and found to agree very closely. In the calculations involving dry dimensions the Spanish measurements were used.

In York the specimens were weighed dry, and then placed in Hanks balanced saline solution for three days. This is much more than enough time to allow the specimens to become fully saturated with the solution, this process taking only a few hours [3, 8]. Imbibing water causes bones to swell slightly, so the width and depth of the hydrated specimens were re-measured. Since the gauge length for the mechanical tests was always $40 \mathrm{~mm}$ their length was not measured. They were re-weighed when wet, surface water having been wiped off immediately previously with an absorbent cloth and their wet modulus of elasticity $E$ determined (see below for mechanical testing methods).

All specimens were then left exposed to room air. The mean weight of the wet specimens was 1.0258 times the original dry weight. After 23 hours it was 1.0074 times as large, after 45 hours 1.0060 times as large and after 118 hours (nearly five days) 1.0066 times as large, a slight increase being shown by virtually all the specimens. The slight increase was probably due to the changing humidity of the air, and the specimens were considered to be fully 'room dry.' All specimens had their room-dry $E$ determined as described below. Those specimens to be tested in impact when wet were placed in Hanks solution for 26-30 hours.

\section{Young's Modulus of Elasticity $(E)$}

All specimens were first tested wet in 3-point bending in an Instron table testing machine, the value of stiffness being taken from the slope up to $10 \mathrm{~N}$ load. The head speed was $2 \mathrm{~mm} / \mathrm{minute}$, resulting in the loading lasting about 10 seconds. $10 \mathrm{~N}$ produce a maximum strain in specimens of our size and shape considerably less than the yield strain of 


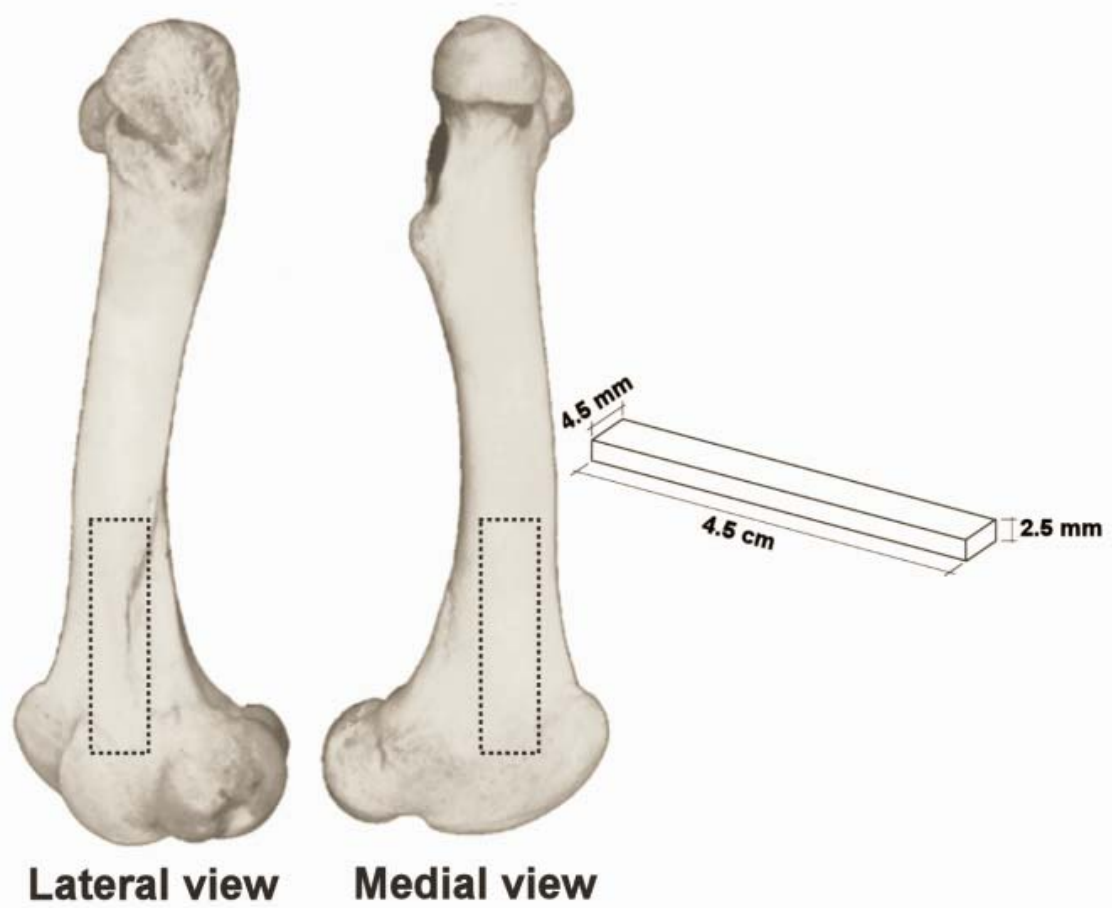

Fig. (1). Section of the femur where bars for mechanical testing were extracted. The specimen seen in the lateral view is called 'external' in the text that seen in the medial view 'internal'. The figure to the right shows the dimensions of the bars.

bone. Machine compliance was tested and found to be negligible. Specimens were oriented with the periosteal side in tension and in determining wet modulus the specimens were kept wet at all times. Stiffness was measured on the chart paper output, the small toe region always found being ignored. Measurements of the deflections produced by two loadings at $10 \mathrm{~N}$ were measured, and the mean value of the two used. The two measurements were essentially identical for the dry specimens; in wet specimens the deflection on the second run was on average $1.5 \%$ greater. Stiffness was converted to $E$ using the standard beam formula: $E=\left(\right.$ Length $^{3} \times$ Load $) /(48 \times$ Deflection $\times($ second moment of area)).

This ignores the deflection due to shear [9]. We did not allow for shear deflections because we did not know the shear modulus of our specimens. The gauge length-to-depth ratio was about 16 . This produced a slight underestimate, about $10 \%$, of $E$. This underestimation was determined in our laboratory from a set of observations on other 'standard' bone specimens using different gauge lengths on the same specimens. Nevertheless we considered our values acceptable because all specimens had very similar values of $E$, which were therefore underestimated by roughly the same amount, and we are concerned here with relative, not absolute values.

All specimens then had their $E$ determined dry, as before. As a result of these procedures, every specimen was tested for its $E$ at $10 \mathrm{~N}$ both wet and dry.

\section{Impact Energy Absorption $(U)$}

All specimens were then tested for their impact energy absorption $U$, half of them wet, half of them dry. Because the specimens were broken in determining $U$ it was not possible to measure the wet $U$ and dry $U$ of any specimen. We tested both specimens from each femur (i.e. one from the internal side and one from the external side) either both dry or both wet. This allowed the comparison of $U$ values for the internal versus the external side of the femora (Fig. 1) but prevented, in contrast to $E$, the comparison of $U$ values for left and right femora of each animal.

Wet specimens were tested immediately on removal from the room temperature solution, and the testing of wet specimens alternated during the day with the testing of dry specimens. The specimens were tested over a period lasting about 4 hours. The specimens were tested, unnotched, either wet or dry, in a Hounsfield plastics impact tester. This consisted of a pendulum that fell, loading the specimen in four-point bending and breaking it. The distance between the outer supports was $40 \mathrm{~mm}$ and the distance between the inner contact lines on the pendulum was $7 \mathrm{~mm}$. Specimens were oriented with the periosteal side in tension. Breaking the specimen required energy and reduced the kinetic energy of the pendulum, and this reduction was measured by the decrease in height reached by the pendulum. $U$ is reported per unit cross-sectional area, as $\mathrm{kJ} / \mathrm{m}^{2}$.

\section{Relationship between Change in Modulus and Energy Absorption with Ca Content}

Because in general there seems to be a relationship between how much the amount of water in wet specimens affects the difference in Young's modulus between wet and dry specimens (see Discussion) we also examined the $\mathrm{Ca}$ value of the femora and the difference in $E$ and $U$ although our samples necessarily had a rather small variation in $\mathrm{Ca}$ values. The difference between these variables tested dry 
minus the values tested wet are henceforth termed $\Delta E$ and $\Delta U$.

\section{STATISTICAL ANALYSIS}

Paired $t$ tests examined whether $E$ values of each single specimen were statistically different when tested wet and dry, and also whether $E$ from left and right femora showed any consistent lateral bias. Because specimens from any femur were tested either dry or wet in impact (and were thus not matched pairs), a one-way ANOVA tested whether $U$ differed between wet and dry impact testing modes. Pearson correlations tested the relationship between variables. Because, as mentioned above, $E$ could be measured both wet and dry on each specimen, the data allow for correlations between $E$ (wet or dry) of the left and right femur, either examining the mean value per femur, or using values for external and internal sides pooled.

Because a perfect correlation could be found even if, for example, one side had consistently exactly twice the $E$ of the other, we also calculated the percentage of the standardized value of the difference between left and right values of $E$ tested either dry or wet. The formula used was as in Alexander et al. [10]: $100 *[(\mathrm{~L}-\mathrm{R}) / 0.5 *(\mathrm{~L}+\mathrm{R})]$ where $\mathrm{L}$ and were left and right values of $E$ tested wet or dry. This shows any net bias towards the left or right ' $B$ '. In addition, we transformed this to measure absolute values irrespective of direction of asymmetry: $\sqrt{ }[\mathrm{B}]^{2}$.

Similarly, a correlation could also be made between $E$ of the internal and external sides of the femur. In contrast, as a destructive test, $U$ was tested either dry or wet for both samples in a bone, thus allowing only the correlation of $U$ of the external vs. that of internal face, but not that of left and right femur. We also performed similar tests of symmetry for external minus internal as those explained for left minus right. In addition, $U$ tested dry vs. wet could be correlated at the hind level by computing the mean for each femur (i.e. both specimens tested wet or dry for the same femur) and correlating it with that of the other femur of the hind.

The correlation between both $\Delta E$ and $\Delta U$ with $\mathrm{Ca}$ content was assessed at two sample sites per femur (i.e., the individual value was the mean of four samples).

All values in the paper are given as means \pm S.E.

\section{RESULTS}

Of the 48 specimens tested, three were excluded from full analysis, one because it was clearly anomalous, being light for its volume, swelling more and having a very low $E$ and $U$ compared with all the other specimens. For the second, we report only the wet $E$, because of a mistake during mechanical testing of dry $E$, which may have damaged it. In the third case, the $U$ was clearly anomalous for some reason, possibly a mistake during testing. For this reason we discarded this value of $U$, but not the wet or dry values of $E$.

\section{Changes in Weight and Dimensions}

Immersing the specimens in water produced a mean increase in weight of $2.6 \%$. The width increased by a mean of $0.6 \%$ and the depth by $1.0 \%$. The mean increase in cross sectional area was $1.7 \%$ and the increase in the second moment of area $(I)$ was $4.1 \%$. The 'wet' dimensions were used in calculating $E$ and $U$ for the wet specimens. This results, of course, in the calculated mechanical values being slightly less than they would be if the 'dry' dimensions had been used.

\section{Young's Modulus $(E)$}

The mean $E$ of the femoral specimens measured when dry was greater than that of the specimens when measured wet (paired comparison $t$, wet $v s$. dry: $19.80 \pm 0.20 v s$. $\left.21.26 \pm 0.20 \mathrm{GPa}, t_{1,45}=9.76, \mathrm{~N}=46 ; \mathrm{p}<0.001\right)$. Note that the specimens measured dry had a value of $E$ only $7.4 \%$ greater than the specimens measured wet, although the difference was highly statistically significant. $E$ tested wet and dry on the same specimens showed a tight correlation $(R=0.72, P<0.001, \mathrm{~N}=46)$.

\section{Impact Energy Absorption $(\boldsymbol{U})$}

There was, in distinction to $E$, a very great difference between the $U$ of the wet and the dry specimens. The wet specimens on average absorbed more than twice as much energy as the dry specimens $(7.20 \pm 0.48$ vs. $3.33 \pm 0.14 \mathrm{~kJ}$ $\mathrm{m}^{-2} F_{1,45}=58.21$, or, considering the mean value per femur: $F_{1,22}=86.77$, both $P<0.001$, Fig. 2).

There was no significant correlation between $U$ tested dry and that tested wet, using the mean of two bars per femur for wet testing and those of the other femur for dry testing; $(R=0.05, P \gg 0.1, \mathrm{~N}=12)$.

\section{U vs. $E$}

$U$ showed no significant correlation with $E$ when tested wet, although the correlation coefficient was reasonably large $(R=0.46, \mathrm{P}=0.13, \mathrm{~N}=12)$. In contrast, the correlation coefficient dropped to near zero for $U v s$. $E$ tested dry $(\mathrm{R}=-$ $0.14, \mathrm{P}=0.66, \mathrm{~N}=12$ ).

\section{Internal vs. External: $E$ and $U$}

$E$ of the external and internal sides correlated just significantly when tested dry $(R=0.43, P=0.039, \mathrm{~N}=23)$, but not when tested wet $(R=-0.02, P>0.1, \mathrm{~N}=22)$. Both internal and external specimens showed a reasonably high correlation between their $E$ value tested wet, and their $E$ value tested dry (for internal specimens, $E$ wet vs. $E$ dry, $R=0.54, P=0.009$; for external specimens, $R=0.83, P<$ $0.001, \mathrm{~N}=22$ and 23, respectively).

Since tests to assess $U$ are destructive, as mentioned above $U$ could be compared only on the internal vs. external sides of each femur. Correlations between $U$ external and $U$ internal approached formal significance when tested wet ( $R$ wet $=0.58, P=0.061, \mathrm{~N}=11$ ), but not when tested dry $(R$ dry $=0.25, P=0.46, \mathrm{~N}=11)$.

The symmetry analyses comparing internal and external sides to assess biases in $E$ and $U$ showed an insignificant 6.4 $\pm 7.8 \%$ bias towards the internal side (i.e. internal was the greater value) in $U$. In absolute terms (i.e. considering biases irrespective of their direction) showed a mean deviation of $28.3 \pm 5.0 \%$. Compared to this, $E$ was more symmetrical: the 


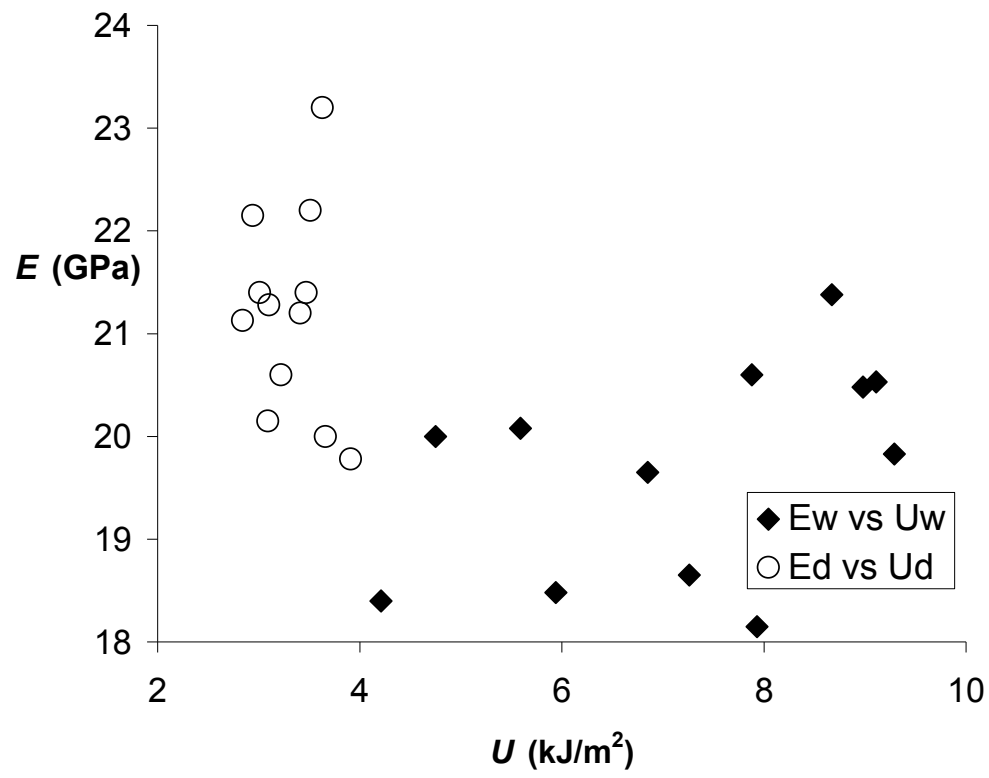

Fig. (2). Relationship between Young's modulus of elasticity $(E)$ and energy required to break specimens in impact $(U)$ in hinds' femora (which was either tested dry or wet for $U, \mathrm{~N}=12$ ). Filled diamonds: $E v s$. $U$ both tested wet, hollow circles: tested dry.

net bias was $1.4 \pm 2.0 \%$ bias towards the internal side when tested wet, and $3.9 \pm 1.3 \%$ when tested dry. The mean absolute bias was $7.4 \pm 1.2 \%$ when tested wet, and $5.8 \pm$ $1.0 \%$ when tested dry.

\section{Left vs. Right: $E$}

The test for $E$ allowed the assessment of whether values on the left femur correlate with values of the right femur. The analysis examining the relationship between left and right femora showed a significant correlation both for $E$ tested wet $(R=0.62, P=0.002, \mathrm{~N}=22)$ and dry $(R=0.58$, $P=0.004, \mathrm{~N}=23$ ). This suggests a coherence between values for femur stiffness between the right and left sides of the animal. Additionally, the measure of absolute deviation from symmetry (i.e. adding deviations to the left and right without considering opposing signs) showed a bias of $3.2 \pm 0.5 \%$ for wet testing and $3.6 \pm 0.9 \%$ for dry testing, whereas the net deviation to one side showed a bias towards the right side of $0.1 \pm 1.1 \%$ for wet testing and $1.6 \pm 1.4 \%$ for dry one.

\section{Effect of Ca on $E, U, \Delta E$ and $\Delta U$}

We correlated mean Ca content of both femora with $E$, $U, \Delta E$ and $\Delta U$ (Figs. 3 and 4). The correlations were not significant for $E$ tested wet or $\Delta E(\mathrm{R}=0.31, P=0.33$ and $R=-0.46, \quad P=0.13$, respectively), although the large coefficient for a sample size of 12 and the fact that $\mathrm{Ca}$ was assessed in other femur regions not adjacent to specimens for mechanical testing suggest that at least $\Delta E$ might become significant with larger sample sizes. In contrast, $\mathrm{Ca}$ was

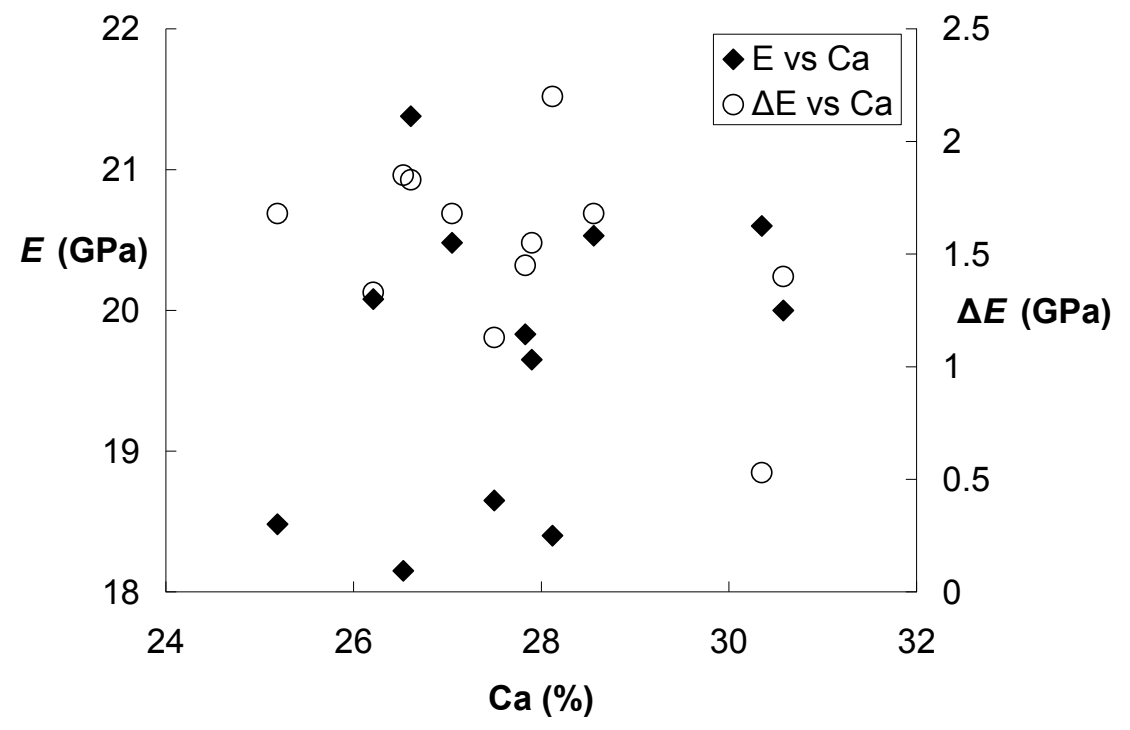

Fig. (3). Relationship between Ca content (assessed in mid femur) and $E$ (tested wet) or $\Delta E$ (taken as the difference between $E$ tested dry minus $E$ tested wet in the same specimens; all tested in lower part of the bone) in hinds' femora $(\mathrm{N}=12)$. Neither relationship was statistically significant (Ca vs. $\Delta E, \mathrm{R}=-0.46, P=0.12$; Ca vs. $E, \mathrm{R}=0.31, P=0.33$ ). 


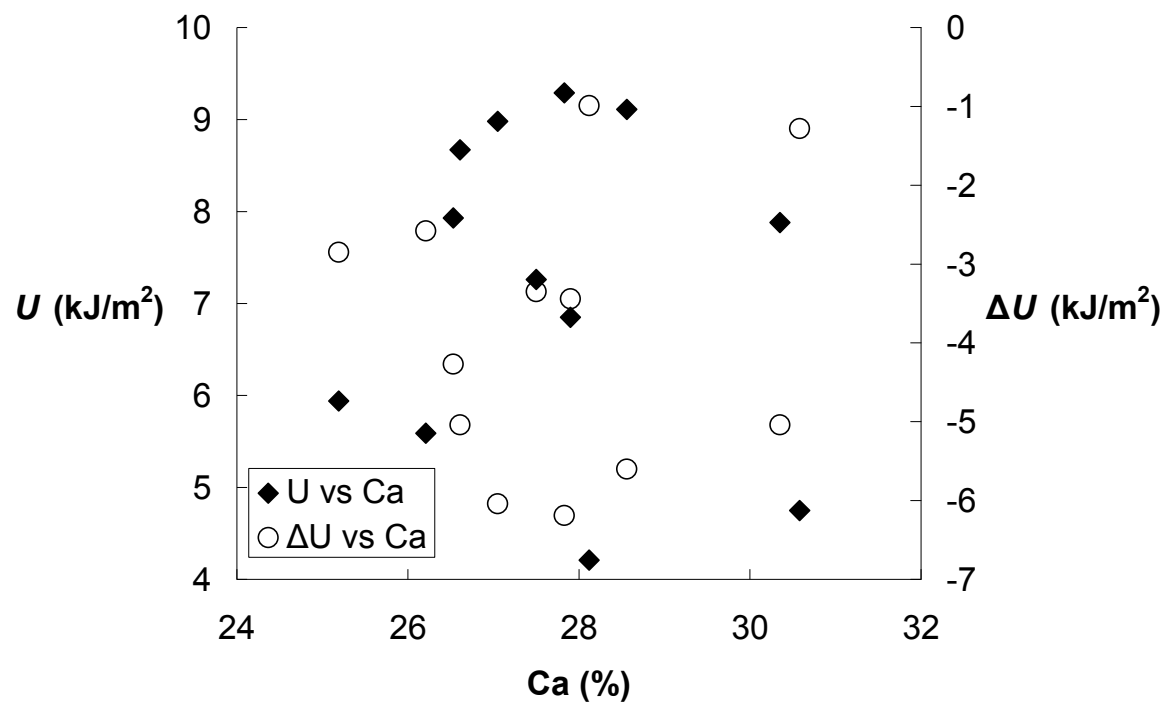

Fig. (4). Relationship between Ca content (assessed in mid femur) and $U$ (tested wet) or $\Delta U$ (taken as the difference between $U$ tested dry in one femur minus $U$ tested wet in the other; all tested in lower part of the femur) in hinds' femora $(\mathrm{N}=12)$.

neither significant nor did it produce large coefficients with $U$ tested wet or $\Delta U(\mathrm{R}=-0.09$, and $R=0.08)$. Surprisingly, $\Delta U$ correlated with $U$ tested wet, but not $U$ tested dry $(\mathrm{R}=-0.98, \mathrm{P}<0.001 v s . \mathrm{R}=-0.14, \mathrm{P}=0.92$, both $\mathrm{N}=12)$, suggesting a very narrow variation in $U$ tested dry $v s$. a rather large one tested wet. However, $U$ and $\Delta U$ did correlate significantly with other minor minerals, even at this sample size (unpublished data, in preparation).

\section{DISCUSSION}

The results show a great effect of hydration in deer femora on impact energy absorption $U$ and a small one on Young's modulus $E$ (Table 2 gives mean values of the main mechanical results for a quick comparison including also previous studies by our group [11]). This, along with the relationship of impact energy with $E$ tested wet but not dry, the lack of correlation between $U$ tested dry and wet in contrast to $E$, the lack of correlation of $U$ with $\mathrm{Ca}$, and the nearly perfect fit of $U$ tested wet with $\Delta U$ in contrast to $U$ tested dry, are all consonant with the suggestion that impact testing measures something concerning the organic phase of bone (which is mainly protein), and that water produces a large increment in $U$ because water plasticises the organic phase [6].

Several lines of evidence suggest that impact energy depends on the organic rather than the mineral phase, and that the organic phase become fully functional in cortical bone when it is wet. The first piece of evidence is that the correlation coefficients for $\mathrm{Ca}$ with $E$ and $\Delta E$ were much higher, 0.31 and -0.46 respectively, than the correlation coefficients of $\mathrm{Ca}$ with $U$ or $\Delta U,-0.09$ and -0.08 , respectively, both tested wet. If a mechanical property depends on the mineral phase it should be less affected by any water absorbed than if it depends on the organic phase. Thus, $E$ decreased from $21.3 \mathrm{GPa}$ dry to $19.8 \mathrm{GPa}$ wet, a reduction of only $7 \%$. This is partially explained simply by the change in density, because the bone absorbed $2.6 \%$ water. In contrast, $U$ increased twofold when the specimens were wet rather than dry. This large change in $U$ cannot be accounted for by the relatively small change in bone density. A corollary of this is that the decrease in $E$ on absorbing water should be greater the lower the amount of $\mathrm{Ca}$ content in bone. Thus, in antler, whose mineral content is ca. $60 \%$ [11-15] we found that the value of $E$ of wet antler was less than half that of dry antler, $17.5 \mathrm{GPa}$ dry and $7.3 \mathrm{GPa}$ wet. In comparison, deer femur bone has $72 \%$ mineral content (Olguin et al. unpublished data). The effect of hydration in increasing $U$ should also be larger in poorly mineralised antler than in the well-mineralised femur and, in fact, $U$ is increased so much that antler specimens often do not break in impact.

A second piece of evidence is the different behaviour of $E$ and $U$ in the correlations between dry values and wet values. As $E$ depends mainly on the mineral phase, it is expected that the variations between hinds in $\mathrm{Ca}$ affect both

Table 2. Summary of Mechanical Properties of Cortical Bone from Hind Femurs Assessed in this Study and those Assessed in a Previous Study by Our Group (Currey et al., 2009) which Includes antler Cortical Bone

\begin{tabular}{|c|c|c|c|c|}
\hline$E(\mathrm{GPa})$ & 7.3 & 17.5 & 19.8 & 21.3 \\
\hline Bending strength (MPa) & 116 & 352 & 263 & - \\
\hline Work to fracture $\left(\mathrm{kJ} / \mathrm{m}^{2}\right)$ & 31.0 & 23.4 & 9.6 & - \\
\hline
\end{tabular}


$E$ tested wet and dry, therefore they should correlate. In contrast, if $U$ is affected mainly by changes in the organic phase, it is very likely that the organic phase becomes functional in femora only when hydrated, and is not functioning properly when in the dry state. Thus, differences in amount of organic phase between individual hinds should affect the wet but scarcely the dry state. Indeed the correlation coefficient of $U$ wet and $U$ dry was small and statistically insignificant. Furthermore, the correlation of the difference (always an increase) between $U$ in the dry to the wet state (i.e. $\Delta U)$, showed a nearly perfect fit $(R=-0.98)$ with $U$ tested wet, but a very low fit with $U$ tested dry $(R=0.14)$.

Our bone specimens whose moduli were tested dry in York had slightly lower mean value than those tested wet from the same femora in Spain, 21.1 GPa vs. $22.4 \mathrm{GPa}$ respectively. We do not know the reason for this difference. However, since the wet and dry specimens tested in York had such a small difference in mean modulus, we did not consider this a cause for concern.

A question that arises is whether our results on cortical bone specimens are similar to those of previous workers. Our results for $E$ show a somewhat smaller difference between dry and hydrated bone (our wet bone has a 7\% lower mean $E$ than dry bone, less than reported previously in the literature). However, this may be because the $\mathrm{Ca}$ content of our hind femora was higher than that of other bones reported. An early experiment by [1] found that wet human cortical bone had an $E$ of wet specimens about $19 \%$ less than that of dry specimens. [3] reported (on their method nearest to ours) that $E$ was about $10 \%$ less in human hydrated specimens. [2] showed a $20 \%$ reduction in the rather poorly mineralised walrus humerus. Long bones from adult humans seem to have lower mineralisation than adult deer long bone [16]. The very poorly mineralised deer antler, reported in Currey et al. [11] showed a very large difference, the wet antler specimens being $58 \%$ less stiff $(7.3 \mathrm{GPa} v s$. $17.5 \mathrm{GPa})$, though strangely Chen et al. [17] found only a small, 8\%, difference between the wet and dry antler. Nevertheless, overall these results suggest that, not surprisingly, the more highly mineralised a tissue the less the reduction in modulus on wetting, and our results are not out of line.

We could find no papers reporting the results of impact energy absorption on hydrated and dehydrated bone. Workers have reported in the reduction in quasi-static work in bone and in dentine, a closely related tissue, as a result of dehydration (e.g. [1, 18]). Wet bone requires considerably more work to break it quasi-statically than does dry bone. Our impact results find the same thing though numerically, of course, the values differ.

The effect of hydration on impact energy absorption is startling. For dry bone, wet bone and dry antler they are, respectively: $3.3,7.2$, and $47.5 \mathrm{kN} \mathrm{m}^{-2}$ respectively [11]. Wet antler could not be tested properly, because specimens are so tough that they frequently do not break. It clearly has a very high impact energy absorption, but a low modulus of elasticity. Dry antler requires much more energy to fracture in impact than does wet bone, and dry bone is even worse. Indeed, dry bone has only $7 \%$ of the impact energy absorbing capacity of dry antler.
Because antler shows a great impact absorbing ability than wet bone even in a dry state [11], it would be interesting to examine whether the protein or organic component in functioning wet bone is different from that in functioning dry antler, or whether the difference is primarily one of amount.

Although there is almost certainly an overall effect of mineral content on the difference between wet and dry bone in Young's modulus, we found no significant effect in our bones. We could find no data (except the present) concerning the effect of mineral content on the impact energy absorption of wet and dry mineralised tissues. It is not surprising that there were no statistically significant differences for $E$ or $U$, because the variation in $\mathrm{Ca}$ content is so low. However, the fact that the insignificant correlation coefficient is higher for Young's modulus than for impact energy absorption does suggest that there are effects, and that these appear to be more closely related to Young's modulus than to impact energy. Ca has a greater correlation with $E$ than with $U$. It is possible that this is because $E$ can be determined more precisely. This is consistent with Currey et al. [19] and reflects the smaller coefficient of variation for $E$ than for measures of energy absorption.

An interesting point that will be explored later (in preparation; unpublished data on the samples of this experiment) is that, despite a sample size sufficiently small that the relationship of $\mathrm{Ca}$ and $E$ was not significant, other minerals examined in the sample did show significant correlations with $U$ and $\Delta U$. This may suggest the important role of some of these minerals in determining $U$ or else, in their association with organic components that in turn determine $\mathrm{U}$.

The fact that $E$ does not predict (or is not correlated with) $U$ is not surprising because a high value of $E$ in the rather limited range found here is associated with two contrary things: a high resilience, that is the area under the pre-yield part of the load-deformation curve, but a greater brittleness, that is, less post-yield deformation. These two features act against each other as regards impact energy absorption.

\section{CONCLUSIONS}

Hydration of femoral bone has a far greater effect on $U$ than on $E$ suggesting that $U$ depends on the organic component which becomes plasticised and fully functional when wet, whereas $E$ depends mainly on the mineral phase which is not greatly affected by moderate amounts of hydration.

Being dry reduces impact energy to a far greater extent than it increases stiffness. We therefore conclude that because the relatively highly mineralised ordinary bone, were it to be used for antlers would like ordinary antler tissue necessarily be dry it would [11], being very brittle, be useless in the role of antler, which involves considerable impacts at the beginning of a fight.

\section{ACKNOWLEDGEMENTS}

This research has been partly funded by MCEI-FEDER project CGL2008-00749/BOS. The authors wish to thank 
Yolanda Fierro and IREC staff for supplying the bone femora.

\section{REFERENCES}

Evans FG, Lebow M. Regional differences in some physical properties of the human femur. J Appl Physiol 1951; 3: 363-72.

[2] Brear K, Currey JD, Pond CM, Ramsay MA. The mechanical properties of the dentine and cement of the tusk of the narwhal Monodon monoceros compared with those of other mineralized tissues. Arch Oral Biol 1990; 35: 615-21.

[3] Nyman JS, Roy A, Shen X, Acuna RL, Tyler JH, Wang X. The influence of water removal on the strength and toughness of cortical bone. J Biomech 2005; 39: 931-8.

[4] Akhtar R, Darymond MR, Almer JD, Mummery PM. Elastic strains in antler trabecular bone determined by synchrotron X-ray diffraction. Acta Biomater 2008; 4: 1677-87.

[5] Krauss S, Fratzl P, Seto J, et al. Inhomogeneous fibril stretching in antler starts after macroscopic yielding: indication for a nanoscale toughening mechanics. Bone 2009; 44(6): 1105-10.

[6] Porter D. Pragmatic multiscale modelling of bone as a natural hybrid nanocomposite. Mat Sci Eng A 2004; 365: 38-45.

[7] Wysolmerski JJ. The evolutionary origins of maternal calcium and bone metabolism during lactation. J Mammary Gland Biol 2002; 7: 267-76.

[8] Utku FS, Klein E, Saybasili H, Yucesoy CA, Weiner S. Probing the role of water in lamellar bone by dehydration in the environmental scanning electron microscope J Struct Biol 2008; 162: 361-7.

[9] Spatz HC, O'Leary EJ, Vincent JFV. Young's moduli and shear moduli in cortical bone. Proc R Soc Lond B 1996; 263B: 287-94.
[10] Alexander RM, Brandwood A, Currey JD, Jayes AS. Symmetry and precision of control of strength in limb bones of birds. J Zool (Lond) 1984; 203:135-43.

[11] Currey JD, Landete-Castillejos T, Estevez J, et al. The mechanical properties of deer antler bone when used in fighting. J Exp Biol 2009; (in press).

[12] Currey JD. Mechanical properties of bone tissues with greatly differing functions. J Biomech 1979; 12: 313-9.

[13] Landete-Castillejos T, Garcia A, Gallego L. Body weight, early growth and antler size influence antler bone mineral composition of Iberian Red Deer (Cervus elaphus hispanicus). Bone 2007; 40: 2305.

[14] Landete-Castillejos T, Estevez JA, Martínez A, Ceacero F, Garcia A, Gallego L. Does chemical composition of antler bone reflect the physiological effort made to grow it? Bone 2007; 40: 1095-102.

[15] Landete-Castillejos T, Currey JD, Estevez JA, Gaspar-Lopez E Garcia A, Gallego L. Influence of physiological effort of growth and chemical composition on antler bone mechanical properties. Bone 2007; 41: 794-803.

[16] Currey JD, Pond CM. Mechanical properties of very young bone in the axis deer (Axis axis) and humans. J Zool (Lond) 1989; 218: 5967.

[17] Chen P-Y, Stokes AG, McKittrick J. Comparison of the structure and mechanical properties of bovine femur bone and antler of the North American elk (Cervus elaphus canadensis). Acta Biomater 2009; 5: 693-706.

[18] Jameson MW, Hood JAA, Tidmarsh BG. The effects of dehydration and rehydration on some mechanical properties of human dentine. J Biomech 1993; 26: 1055-65.

[19] Currey JD, Pitchford JW, Baxter PD. Variability of the mechanical properties of bone, and its evolutionary consequences. J R Soc Interface 2007; 4: 127-35.

(c) Currey et al.; Licensee Bentham Open.

This is an open access article licensed under the terms of the Creative Commons Attribution Non-Commercial License (http://creativecommons.org/licenses/by$\mathrm{nc} / 3.0 /$ ), which permits unrestricted, non-commercial use, distribution and reproduction in any medium, provided the work is properly cited. 